Journal of Patient-Centered

Volume 2

Issue 4 -- Integrative Medicine

Article 6

$11-20-2015$

\title{
Should Primary Care Physicians Address Sleep to Improve Weight Loss in Obese Patients? A Clin-IQ
}

Kjersti E. Knox

Follow this and additional works at: https://aah.org/jpcrr

Part of the Alternative and Complementary Medicine Commons, Integrative Medicine Commons, Nutritional and Metabolic Diseases Commons, and the Primary Care Commons

\section{Recommended Citation}

Knox KE. Should primary care physicians address sleep to improve weight loss in obese patients? A ClinIQ. J Patient Cent Res Rev. 2015;2:197-200. doi: 10.17294/2330-0698.1205

Published quarterly by Midwest-based health system Advocate Aurora Health and indexed in PubMed Central, the Journal of Patient-Centered Research and Reviews (JPCRR) is an open access, peer-reviewed medical journal focused on disseminating scholarly works devoted to improving patient-centered care practices, health outcomes, and the patient experience. 


\title{
Should Primary Care Physicians Address Sleep to Improve Weight Loss in Obese Patients? A Clin-IQ
}

\author{
Kjersti E. Knox, MD \\ Department of Family Medicine, Aurora Sinai Medical Center, Aurora University of Wisconsin Medical Group, Aurora \\ Health Care, Milwaukee, WI
}

\begin{abstract}
Obesity is a commonly encountered problem in the primary care setting. Simultaneously, sleep is seen to hold an increasingly important role in many components of health and wellness. A review of the literature was performed to determine if improving sleep positively impacts weight loss in obese adults. The evidence reviewed suggests that improving patients' sleep may initially improve patient weight loss; however, current studies do not show a sustained statistically significant impact. Until higher powered and higher quality studies are completed, there are no clear evidence-based guidelines for primary care physicians to follow regarding sleep and obesity. (J Patient-Centered Res Rev. 2015;2:197-200.)
\end{abstract}

Keywords obesity, sleep, weight loss, primary care

\section{Clinical Question}

In obese adults, does improving sleep improve weight loss?

\section{Answer}

Inconclusive. The evidence reviewed supports that improving sleep initially improves weight loss; however, in the setting of limited sample sizes, specialized recruitment and limited follow-up, statistically significant weight loss was not shown.

Date answer was determined: June 2015.

\section{Level of evidence: B.}

Inclusion criteria: Clinical trials searchable in PubMed from the last 10 years (June 2005-June 2015).

Exclusion criteria: Incomplete/ongoing studies; no matched comparison or control group described; proposed intervention could not be performed by a primary care provider in an outpatient clinic; patient population was not recruited from the general

Correspondence: Kjersti E. Knox, MD, 1020 N. 12th Street, Milwaukee, WI, 53233, T: 414-219-5259, F: 414-219-5960,

Email: kjersti.knox@aurora.org population; patients were not overweight or obese at study start; outcomes were not reported in body mass index (BMI) change or weight loss; a validated sleep assessment tool was not used.

\section{Summary of the Problem}

Obesity affects more than $30 \%$ of adults in the United States and has remained at this level for over a decade. ${ }^{1}$ Additionally, obesity has far-reaching health effects, including decreased quality of life and increased risk for comorbid disease. ${ }^{2}$ Primary care physicians (PCPs) are challenged with treating obese patients with the tools now available. Empowering PCPs with evidencebased strategies to address obesity in the primary care setting is essential to prevent further increases in obesity and to treat existing disease.

Treatment of disordered sleep is emerging as a low-risk intervention targeting multiple important health problems, including obesity. Evidence shows that changes in caloric intake, ${ }^{3}$ brain activation ${ }^{4}$ and biochemical processing ${ }^{5}$ occur with less sleep. Collectively these studies suggest that sleep may have an integral role in the development and treatment of obesity. Sleep has increasingly gained importance in integrative medicine and has been placed on par with topics such as nutrition, exercise and stress as pillars of wellness. ${ }^{6}$ Counseling and supporting patients in good sleep hygiene is easily done in a primary care setting 
through short motivational interviewing sessions — the foundational tool of the PCP. ${ }^{7}$ Motivational interviewing lends itself to collaboration with patients for patient-centered, holistic care. Additionally, integrative methods such as mindfulness sleep induction, progressive muscle relaxation, guided imagery and over-the-counter supplements (e.g. melatonin) have been suggested to improve sleep ${ }^{8}$ and can be taught to patients in a primary care setting.

\section{Summary of the Evidence}

Of the initial 67 clinical trials identified by our search strategy, two studies satisfied the inclusion/exclusion criteria. ${ }^{9,10}$ Both suggested a relationship between sleep and weight loss without ultimately showing significance (Table 1). Each of these two studies recruited participants from the general population, used the self-reported Pittsburgh Sleep Quality Index (PSQI) to assess sleep, measured percent weight loss for participants, and had short follow-up periods (24 months or less). Neither study separated individuals who were overweight (BMI 25-30) from those who were obese $(B M I \geq 30)$ or used formal sleep study evaluation.

In the first study, Logue et al. ${ }^{9}$ recruited patients from a family medicine clinic if they had BMI of 25.0-39.9 $\mathrm{kg} / \mathrm{m}^{2}$, were $18-84$ years old, were not pregnant or two months postpartum and had no known history of: vascular and endocrine comorbidities, bariatric surgery, use of weight loss medications, sleep disorders/ongoing sleep disruption (i.e. shift work) or psychiatric comorbidities. The PSQI and Sleep Timing Questionnaire were used. A total of 46 patients were randomized to either the Better Weight (BW) intervention, which included diet, exercise and development of coping skills, or to the Better Weight/ Better Sleep (BWBS) intervention, which provided the same intervention as the BW group with additional sleep counseling. Patient sleep was assessed three times over 12 weeks. Intention-to-treat analysis was performed. Dropout rates were similar in both groups, with 23 patients (12 BW, $11 \mathrm{BWBS}$ ) completing the intervention.

Patients randomized to the two groups had similar distribution of BMI and poor overall sleep quality at baseline as well as similar employment and socioeconomic status. Age distribution, education and race differed between the groups, with more middleaged participants in the BW arm $(60.9 \%)$, a higher percentage of individuals completing more than 12 years of education $(60.9 \%$ vs. $82.6 \%)$ in the BWBS arm and also a higher percentage of African Americans $(39.1 \%$ vs. $60.9 \%)$ in the BWBS group. Importantly, the BWBS group ate significantly fewer added sweets $(\mathrm{P}=0.009)$ and added fats $(\mathrm{P}<0.0001)$ at baseline. ${ }^{9}$

Table 1. Summary of evidence

\begin{tabular}{|c|c|c|}
\hline & BW vs. BWBS $^{9}$ & Sleep association ${ }^{10}$ \\
\hline Trial format & Randomized control trial, single site & Embedded cohort, multicenter \\
\hline No. at start (completed) & $46(23)$ & $245(198)$ \\
\hline Duration & 12 weeks & 24 months \\
\hline Measurement & Percent weight loss & Percent weight loss \\
\hline Intervention & Sleep counseling & $\mathrm{n} / \mathrm{a}$ \\
\hline Outcome & $\begin{array}{l}\text { Significantly increased weight loss in } \\
\text { intervention group at } 12 \text { weeks; however, } \\
\text { results were nonsignificant when adjusted } \\
\text { for sweets and fats intake at baseline }\end{array}$ & $\begin{array}{l}\text { Significantly improved weight loss in group } \\
\text { with longer sleep duration and better quality } \\
\text { of sleep at } 6 \text { months, but results were } \\
\text { nonsignificant by } 24 \text { months }\end{array}$ \\
\hline Limitations & Small sample size; length of follow-up & Recruitment methodology; length of follow-up \\
\hline
\end{tabular}

BW, better weight; BWBS, better weight/better sleep; n/a, not applicable. 
The authors found that the BWBS group's mean percentage of weight loss was significantly more than the $\mathrm{BW}$ group $(\mathrm{P}=0.04)$. However, when controlling for differences in intake of sweets and fats at baseline, the sample size became too small to show statistical significance $(\mathrm{P}=0.06)$. Interestingly, sleep efficiency increased equally in both groups $(\mathrm{P}=0.52)$. Limitations of the study were largely sample size, participant completion rate and short study length (12 weeks). ${ }^{9}$

In the second study, Thomson et al. ${ }^{10}$ used an embedded cohort in an ongoing randomized control trial. Patients from the general population were recruited to a multicenter, multistate trial through flyers, email, radio and survey of electronic medical records. Participants were randomized to take part in a commercial weight loss program or to receive counseling from a dietician; all were followed for 24 months. Participants were $\geq 18$ years old, had BMI $25-40 \mathrm{~kg} / \mathrm{m}^{2}$ and were at least $15 \mathrm{~kg}$ overweight. Patients were excluded based on current pregnancy or intended pregnancy in the subsequent two years after study start, history of eating disorders or food restrictions, inability to perform baseline fitness testing, and any psychiatric illness or "any other condition that, in the investigator's judgment, would interfere with participation in the trial." 10

This embedded study was an ancillary cohort study that started after initial patient recruitment for the parent randomized control trial. The original randomization was not used; instead, cohorts were built from participants in the parent study who had lost 1 or more $\mathrm{kg}$ at 6 months. A total of 245 female patients qualified for the embedded study, with 198 completing the full 24-month follow-up. Cohort outcomes were compared based on: 1) patient-reported hours slept at baseline $>7$ or $\leq 7$, and 2) poor quality of sleep based on a component sleep score of 0 (good sleep) or $\geq 1$ (poor sleep). Groups were adjusted for confounders of age, BMI, race/ethnicity and intervention arm in the parent study. The two groups differed based on age and menopausal status (with longer sleep duration associated with younger, premenopausal participants, consistent with previously established norms). Sleep quality was assessed using the PSQI at 0 and 6 months. ${ }^{10}$
The authors found a significant difference in ability to obtain weight loss $>10 \%$ of baseline weight at 6 months in the "good sleep" group (adjusted risk ratio: 0.67 ) and in women sleeping $>7$ hours/night (adjusted risk ratio: 0.70 ). This pattern was continued at 12, 18 and 24 months; however, the effect decreased and was nonsignificant at 24 months. Limitations of this study include the nonrepresentative volunteer sample of the original randomized control trial, subsequent lack of clarity on exclusion criteria and its limiting to patients with successful weight loss at 6 months. The study sample also differed in accepted patterns of spectrum of sleep duration, with very few participants in this study sleeping $>9$ hours at baseline.

\section{Conclusions}

Obesity treatment and prevention is an ongoing challenge for adult patients and their primary care physicians. Initial evidence suggests that improving patient sleep may improve patient weight loss, however, a sustained statistically significant effect has not been shown in current studies. The question of whether PCPs should emphasize sleep in the treatment of obese patients remains unanswered. Further research efforts — including appropriately powered, high-quality randomized control trials with systematic recruitment and attention to specific demographics (e.g. sex, age, and race) - are needed.

\section{Patient-Friendly Recap}

- Preventing and treating obesity is an ongoing challenge for patients and their primary care physicians.

- The authors asked whether current evidence indicates improved sleep leads to weight loss in obese patients.

- They found that while improving a patient's sleep pattern may result in initial weight loss, a sustained effect has not been sufficiently proven by published clinical trials.

- Further research is needed before physicians can be instructed to emphasize sleep when treating obesity. 


\section{Acknowledgments}

The Clin-IQ teaching materials used for this project were provided by Oklahoma Shared Clinical \& Translational Resources, funded by grant number NIGMS U54GM104938 (National Institute of General Medical Sciences, National Institutes of Health).

\section{Conflicts of Interest}

None.

\section{References}

1. Ogden CL, Carroll MD, Kit BK, Flegal KM. Prevalence of childhood and adult obesity in the United States, 2011-2012. JAMA. 2014;311:806-14. CrossRef

2. U.S. Department of Health and Human Services, National Institutes of Health. Managing overweight and obesity in adults. Systematic evidence review from the obesity expert panel, 2013. https://www.nhlbi.nih.gov/sites/www.nhlbi.nih. gov/files/obesity-evidence-review.pdf. Accessed June 27, 2015.

3. Calvin AD, Carter RE, Adachi T, et al. Effects of experimental sleep restriction on caloric intake and activity energy expenditure. Chest. 2013;144:79-86. CrossRef

4. St-Onge MP, McReynolds A, Trivedi ZB, Roberts AL, Sy $M$, Hirsch J. Sleep restriction leads to increased activation of brain regions sensitive to food stimuli. Am J Clin Nutr. 2012;95:818-24. CrossRef
5. Achike F, To NH, Wang H, Kwan CY. Obesity, metabolic syndrome, adipocytes and vascular function: A holistic viewpoint. Clin Exp Pharmacol Physiol. 2011;38:1-10. CrossRef

6. Arizona Center for Integrative Medicine. Sleep \& health (curriculum from Integrative Medicine in Residency program). http://integrativemedicine.arizona.edu/program/2011 IMR_3_Year/sleep_health/sleep_health/1.html. Accessed June 30, 2015.

7. VanBuskirk KA, Wetherell JL. Motivational interviewing with primary care populations: a systematic review and metaanalysis. J Behav Med. 2014;37:768-80. CrossRef

8. Rakel D. Improving and maintaining a healthy sleep-wake cycle (patient handout from the Integrative Medicine Program, Department of Family Medicine, University of Wisconsin School of Medicine and Public Health). http://www.fammed. wisc.edu/sites/default/files/webfm-uploads/documents/ outreach/im/handout_sleep.pdf. Accessed June 30, 2015.

9. Logue EE, Bourguet CC, Palmieri PA, et al. The better weight-better sleep study: a pilot intervention in primary care. Am J Health Behav. 2012;36:319-34. CrossRef

10. Thomson CA, Morrow KL, Flatt SW, et al. Relationship between sleep quality and quantity and weight loss in women participating in a weight-loss intervention trial. Obesity (Silver Spring). 2012;20:1419-25. CrossRef

(C) 2015 Aurora Health Care, Inc. 